\title{
Uma Aplicação de Geometria Diferencial à Indústria: molde para empacotamento automático
}

\author{
Cinthya Maria Schneider Meneghetti Rodrigo Barbosa Soares \\ Instituto de Matemática, Estatística e Física, IMEF, FURG, \\ 96203-900, Rio Grande, RS \\ E-mail: cinthya.schneider@gmail.com, rodrigosoares@furg.br,
}

\author{
Adriano Mansur P. Zaher \\ Universidade Federal do Rio Grande \\ 96203-900, Campus Carreiros, Rio Grande, RS \\ E-mail: adrianomansur@yahoo.com.br
}

\section{RESUMO}

A criação de um processo suave para embalar itens de produção é um problema bastante comum na indústria. Geralmente, o material utilizado para embalar é desenrolado de um rolo horizontal e desliza em uma superfície curva, chamada de molde, a qual serve para auxiliar o material a formar um cilindro vertical onde ele, o material, molda-se contra a parede cilíndrica e é selado ao longo da borda dianteira a fim de formar um tipo de embalagem (por exemplo uma embalagem de plástico). Os itens de produção são então colocados na embalagem, a parte superior é fechada e a embalagem é retirada do cilindro. O problema com esse processo é que se o molde não possuir a forma apropriada o material utilizado na embalagem pode apresentar dobras fazendo com que o processo seja interrompido.

Desta maneira, o problema geométrico que surge é determinar a forma apropriada do molde para que o processo ocorra da forma mais suave possível. Como o molde é uma superfície de transição de um plano para um cilindro, é esperado que o molde seja isométrico ao plano, bem como ao cilindro. Isto significa que o molde deve ser uma superfície desenvolvível.

Segundo [?], para obter um molde de uma máquina de empacotar de modo que as embalagens não apresentem dobras ou rasgos usa-se uma superfície desenvolvível. A superfície resultante é um molde que contém uma região triangular plana. De acordo com [?], obtém-se a mesma conclusão, entretanto, há também resultados de molde para seções retangulares.

O objetivo deste trabalho é compreender o estudo feito por [?] e [?] para então mostrar uma aplicação da Geometria Diferencial à indústria.

O conceito fundamental que é estudado no trabalho é o de superfície desenvolvível. Estas superfícies são casos particulares de superfícies regradas as quais possuem o mesmo plano tangente em todos os pontos ao longo de uma geratriz. Essas superfícies são isométricas ao plano e portanto possuem a mesma curvatura Gaussiana do plano, que é identicamente nula. Curvas correspondentes em superfícies isométricas têm a mesma curvatura geodésica em pontos correspondentes. Todo mapeamento isométrico é conforme e uma geodésica em uma superfície desenvolvível corresponde a uma reta em um plano.

Os conceitos de Geometria Diferencial necessários para compreender os cálculos deste trabalho são: fórmulas de Frenet-Serrat, superfícies regradas, superfícies desenvolvíveis, isometria, primeira forma fundamental, vetor normal unitário e curvatura Gaussiana [?], [?] e [?].

As superfícies desenvolvíveis são utilizadas para construir cascos de navios, roupas, calçados e partes de carro e entre outras. 
Este trabalho é parte do trabalho de conclusão de curso (TCC) do estudante Adriano Zaher do curso de Matemática Aplicada Bacharelado da Universidade Federal do Rio Grande (FURG). Palavras-chave: Geometria Diferencial, superfície desenvolvível, molde

\section{Referências}

[1] Boersma,J; Molenaar; J., Geometry of the shoulder of a packaging machine. SIAM Rev.37, n. 3 (1995), 406-422.

[2] Do Carmo, M.P., Geometria Diferencial de Curvas e Superfícies. 5. ed. Rio de Janeiro: SBM, 2012

[3] Massachusetts Institute of Technology. Differential geometry of developable surfaces. Disponível em ¡http://web.mit.edu/hyperbook/Patrikalakis-Maekawa-Cho/node190.htmli. Acesso em: 24 fev.2014.

[4] Mot, E., The "shoulderproblem" of forming, filling and closing machines for pouches. Appl. Sci. Res., n, 27 (1973), 1-13.

[5] Oprea, J., Differential Geometry and Its Applications. 2. ed. Washington, DC: The Mathematical Association of America, 2007. 